\title{
Influence of Cranberry Soil Surface Characteristics on the Activity of Dichlobenil
}

\author{
Hilary A. Sandler ${ }^{1}$ and Carolyn J. DeMoranville ${ }^{2}$ \\ Cranberry Experiment Station, University of Massachusetts, East Wareham, \\ MA 02538-0569
}

Additional index words. Vaccinium macrocarpon, Cuscuta gronovii, dodder, integrated pest management, leaf litter, preemergence herbicides, sanding

\begin{abstract}
Field conditions associated with commercial cranberry (Vaccinium macrocarpon Ait.) production were simulated in greenhouse studies to determine the effect of soil surface characteristics on dichlobenil activity. Sand was compared with organic matter, in the form of leaf litter, as the surface layer. A seedling bioassay using alfalfa (Medicago sativa $\mathrm{L}$.), a dichlobenil-sensitive plant, was employed to determine root growth response on herbicide-treated soil. When the herbicide was applied to a sand surface, root growth was greater as time after application elapsed, indicating loss of herbicide activity. Conversely, the presence of organic matter on the surface prolonged the activity of the herbicide. Composition of the surface layer was more important than the depth of the layer in determining herbicide persistence. The influence of cultural practices, such as the application of sand or the removal of surface debris, on herbicide activity should be considered when planning weed management strategies for cranberry production. Chemical name used: 2,6-dichlorobenzonitrile (dichlobenil).
\end{abstract}

The application of sand to cranberry beds has been an important part of commercial cranberry production since the early 1800 s (Eck, 1990), and is a common cultural practice in the majority of cranberry production acreage in North America. Between 1 and $5 \mathrm{~cm}$ of sand is applied to cranberry beds during the winter or early spring every 2 to 5 years. Sand is applied to cranberry vines to cover basal wood, anchor woody runners, and encourage lateral shoot production. In addition, sanding may stimulate root growth and encourage decomposition of organic matter (DeMoranville et al., 1996; Strik and Poole, 1995). Sanding also provides some pest management benefits, including burial of cranberry girdler (Chrysoteuchia topiaria Zeller) pupae (Franklin, 1951; Tomlinson, 1937), suppression of fruit rot organisms [Phyllosticta vaccinii Earle; Physalospora vaccinii (Shear) Arx. \& E. Muller; Coleophoma empetri (Rostr.) Petr.; Godronia cassandrae Peck; Phomposis vaccinii Shear in Shear, N. Stevens \& H. Bain;

Received for publication 19 Oct. 1998. Accepted for publication 5 Mar. 1999. We acknowledge the excellent technical support of J. Mason. Reference to a proprietary product does not imply approval or recommendation of the product by the Univ. of Massachusetts to the exclusion of other products that may be suitable. The cost of publishing this paper was defrayed in part by the payment of page charges. Under postal regulations, this paper therefore must be hereby marked advertisement solely to indicate this fact.

${ }^{1}$ Extension Educator, Cranberry IPM; to whom requests for reprints should be sent. E-mail: hsandler@umext.umass.edu

${ }^{2}$ Assistant Professor of Nutrition. and Glomerella cingulata (Stoneman) Spauld. \& H. Schrenk] (H.A. Sandler, unpublished data), and the reduction of seedling emergence of swamp dodder (Cuscuta gronovii Willd. ex R. \& S.) (Sandler et al., 1997).

The removal of abscised leaves is another important cultural and pest management technique in commercial cranberry production. Older leaves abscise from the cranberry plants or are dislodged during harvest. The organic debris is removed during harvest or during a postharvest flooding (DeMoranville, 1998). However, some debris remains on the bed surface and continues to accumulate over time. The organic deposition is periodically covered by a thin layer of sand as described above. A vertical profile consisting of alternating layers of sand and organic matter (also known as stratification) develops over many seasons. At any particular time during the years of commercial production, a layer of either sand or organic material is uppermost and acts as the initial interface with soilapplied chemicals.

In general, soil texture and organic matter content are considered to be important components influencing the behavior and properties of pesticides in soil. Occurring mostly in the form of leaf litter in various stages of decomposition, organic matter is a small but significant component of the surface layer of many commercial cranberry beds (Davenport and DeMoranville, 1993). The unique stratification of the cranberry soil profile may influence the activity and performance of chemicals that are applied to the soil surface. Recent research has indicated that the number of layers in the profile, as well as the depth of the layers, may influence yield as well as soil and water properties (Davenport et al., 1999).
While high rates of the preemergence herbicide dichlobenil are recommended for control of several weeds that occur on cranberry farms (Sandler and Bewick, 1999), low rates are recommended for control of dodder. Applications must be made as close as possible to the time of dodder seedling emergence to maximize efficacy of these low-rate applications However, even with accurate timing of application, control may be less than satisfactory. Variation in surface layer composition may affect dichlobenil retention and, therefore, overall efficacy.

The objective of this research was to determine the effect of surface composition on the activity of dichlobenil in a simulated cranberry soil. Sand vs. organic matter (in the form of leaf trash) as the surface layers were compared in the greenhouse.

\section{Materials and Methods}

In 1996-97, two experiments, one comparing leaf litter depth and the other sand depth, were conducted in a $40 \%$ shade cloth-covered plastic greenhouse in which daily temperatures ranged from 10 to $30{ }^{\circ} \mathrm{C}$. The experimental units were pots (19-L capacity, 282-mm diameter) filled to a depth of $8 \mathrm{~cm}$ with commercial peat. The peat was then covered with $18 \mathrm{~cm}$ of coarse sand, consisting of particle diameters from 0.5 to $2.0 \mathrm{~mm}$ (Brady and Weil, 1996). Treatments for Expt. 1 (leaf litter depth study) consisted of 0-, 1.3-, 2.5-, 3.8-, or 5.1-cm layers of cranberry leaves placed on top of the peatsand base. In Expt. 2 (sand depth study), pots received a $2.5-\mathrm{cm}$ layer of leaves on top of the peat-sand base, simulating a bed that had not been sanded for several years. Coarse sand was then added to the top of these pots to a depth of $0,1.3,2.5,3.8$, or $5.1 \mathrm{~cm}$ to simulate sanding depth. Leaf litter for both experiments was collected from the 1996 harvest/trash-removal flood at State Bog, East Wareham, Mass. In each experiment, pots were arranged in a randomized complete-block design with five replicates. To consistently maintain field capacity, $8.0 \mathrm{~L} \cdot \mathrm{m}^{-2}$ water was applied to the surface of each pot every 3 to $4 \mathrm{~d}$ throughout the study. Expt. 1 was conducted from Dec. 1996 through Feb. 1997, and Expt. 2 from March through May 1997.

Following treatment establishment and collection of preherbicide core samples from each pot, dichlobenil was applied at the rate recommended for dodder control, $1.34 \mathrm{~kg} \cdot \mathrm{ha}^{-1}$ a.i., on 13 Dec. 1996 (Expt. 1) and 3 Mar. 1997 (Expt. 2). After application, $0.5 \mathrm{~L}$ water was applied to each pot to incorporate the herbicide.

Prior to application of herbicide and at each subsequent sampling date, one composite sample was collected from each replicate pot for an herbicide activity assay. Four sample cores were collected from the top $9 \mathrm{~cm}$ (excluding treatment depth) of each pot using a 25mm-diameter soil probe. The cores from each individual pot were combined and placed into a square petri dish (Integrid $100 \times 15 \mathrm{~mm}$; Becton-Dickinson, Lincoln Park, N.J.) and distributed uniformly, completely filling the dish. In Expt. 1, samples were collected pretreat- 
ment and $3,10,17,24,45$, and $73 \mathrm{~d}$ posttreatment. In Expt. 2, samples were collected pretreatment and $3,10,24,38$, and $73 \mathrm{~d}$ posttreatment.

The general technique for a seedling bioassay to determine activity of herbicide residues (Murray and Santelmann, 1980; Norman and Patten, 1995; O’Donovan et al., 1996; Parker and Ogg, 1990) was modified slightly for this study. Three to $4 \mathrm{~d}$ prior to any sampling date, $\approx 5 \mathrm{~g}$ of alfalfa seeds were placed in a small, round petri dish and submerged in water for $\approx 5$ min. Excess water was drained from the dish. The seeds were then transferred onto moist filter paper in a clean glass petri dish, sealed with opaque laboratory film, and incubated at $24{ }^{\circ} \mathrm{C}$.

On each sampling date, six germinated alfalfa seedlings were taken from the seeding plate and placed equidistant from each other on the surface of the core sample in each petri dish. The seedlings were oriented with the cotyledons $\approx 5 \mathrm{~mm}$ from the top of the dish and all roots extending towards the bottom. The lid was carefully and firmly placed on top of the seedlings to minimize subsequent movement. The initial root length was measured and recorded as well as marked on the dish cover. All petri dishes were incubated in a vertical position (to permit correct root orientation and elongation) at $24{ }^{\circ} \mathrm{C}$ for $7 \mathrm{~d}$, after which root length of each seedling was measured. Treatment effect on root length after $7 \mathrm{~d}$ was determined by subtracting the original root length of each seedling from its final length. The six values obtained from each dish were averaged to obtain a value for root growth from each replicate pot.

Data from each experiment were analyzed separately. Regression analyses of root growth response over time were performed to calculate slopes, intercepts (y), and correlation coefficients $(r)$ for each depth of sand or organic matter. Regression equations were generated using the General Linear Models procedure (SAS Institute, 1988). Differences in slopes were evaluated using a pairwise comparison test. Root extension of alfalfa seedlings grown on the core samples collected prior to herbicide application was compared with that of seedlings grown on the cores collected after herbicide incorporation to determine if herbicide activity was present. Inhibition of root growth in the latter was assumed to indicate the presence of active herbicide in the media.

\section{Results and Discussion}

Root growth response on herbicide-treated media was related to the composition of the surface layer (Table 1). Organic matter on the surface (Expt. 1) was associated with longterm inhibition of seedling root growth. Conversely, root growth increased over time after herbicide was applied to media with a sand surface (Expt. 2).

Regression lines (Fig. 1) predicting change in root growth response over time subsequent to herbicide application were calculated for each treatment (leaf litter or sand) using the data in Table 1. Based on a $t$ test comparison of

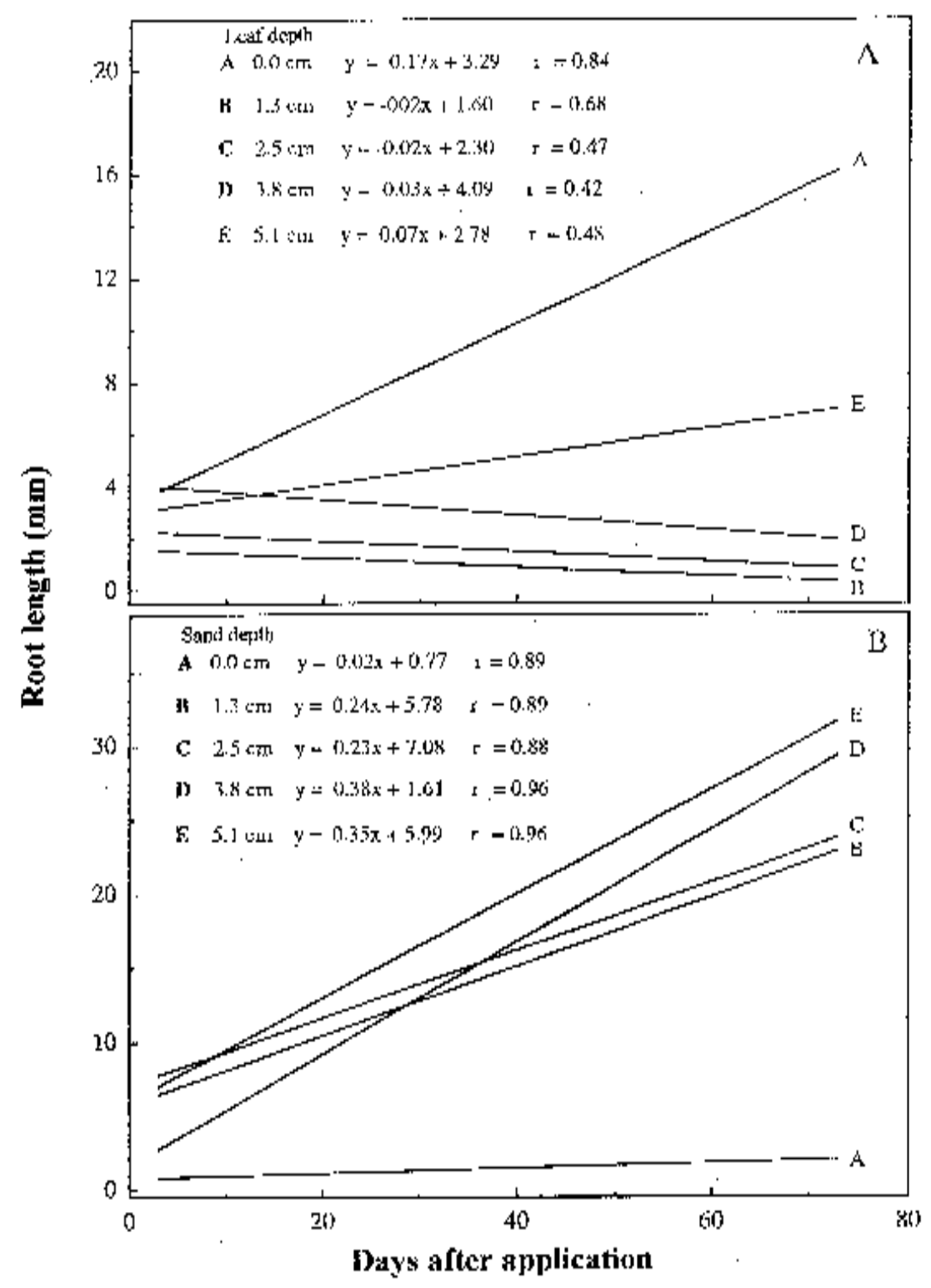

Fig. 1. Root length of alfalfa seedlings incubated on soil covered by various depths of (A) cranberry leaves or (B) sand, subsequently treated with dichlobenil.

Table 1. Alfalfa seedling root lengths $(\mathrm{mm} \pm \mathrm{sE})$ after $7 \mathrm{~d}$ incubation on soil collected from pots containing different depths of leaf litter or sand on the soil surface (means of five replicates). Soil for bioassay was collected from nontreated pots and after application of dichlobenil (1.34 kg.ha-1 a.i.).

\begin{tabular}{|c|c|c|c|c|c|}
\hline \multirow{2}{*}{$\begin{array}{l}\text { Time after } \\
\text { herbicide } \\
\text { application } \\
\text { (d) }\end{array}$} & \multicolumn{5}{|c|}{ Depth of leaves or sand $(\mathrm{cm})$} \\
\hline & 0 & 1.3 & 2.5 & 3.8 & 5.1 \\
\hline \multicolumn{6}{|c|}{ Expt. 1. Depth of leaves } \\
\hline Pre & $31.5 \pm 1.6$ & $37.5 \pm 1.7$ & $38.0 \pm 4.1$ & $38.8 \pm 2.3$ & $36.0 \pm 2.6$ \\
\hline 3 & $3.0 \pm 2.3$ & $1.5 \pm 0.6$ & $3.3 \pm 1.7$ & $3.0 \pm 1.1$ & $2.1 \pm 1.2$ \\
\hline 10 & $6.9 \pm 5.0$ & $1.9 \pm 1.3$ & $1.0 \pm 0.4$ & $2.4 \pm 0.8$ & $4.6 \pm 2.6$ \\
\hline 17 & $2.1 \pm 0.7$ & $1.0 \pm 0.3$ & $0.9 \pm 0.4$ & $6.5 \pm 5.4$ & $0.9 \pm 0.2$ \\
\hline 24 & $8.8 \pm 3.8$ & $0.6 \pm 0.3$ & $2.5 \pm 1.1$ & $3.9 \pm 1.9$ & $4.4 \pm 2.9$ \\
\hline 45 & $15.1 \pm 6.5$ & $1.5 \pm 0.2$ & $2.2 \pm 0.7$ & $1.7 \pm 0.9$ & $11.5 \pm 4.7$ \\
\hline 73 & $14.0 \pm 2.4$ & $0.1 \pm 0.0$ & $0.5 \pm 0.2$ & $2.0 \pm 0.6$ & $3.8 \pm 1.8$ \\
\hline \multicolumn{6}{|c|}{ Expt. 2. Depth of sand } \\
\hline Pre & $40.0 \pm 2.3$ & $37.9 \pm 1.7$ & $32.3 \pm 0.8$ & $37.6 \pm 1.7$ & $25.4 \pm 2.1$ \\
\hline 3 & $0.8 \pm 0.6$ & $3.5 \pm 2.4$ & $3.1 \pm 2.5$ & $0.6 \pm 0.2$ & $3.4 \pm 2.4$ \\
\hline 10 & $0.8 \pm 0.2$ & $12.5 \pm 5.9$ & $14.4 \pm 3.9$ & $4.6 \pm 1.5$ & $13.0 \pm 6.3$ \\
\hline 24 & $1.6 \pm 0.2$ & $12.6 \pm 3.1$ & $13.2 \pm 3.8$ & $11.6 \pm 2.4$ & $16.4 \pm 2.0$ \\
\hline 38 & $1.2 \pm 0.1$ & $11.1 \pm 3.3$ & $15.2 \pm 3.7$ & $20.6 \pm 2.5$ & $17.6 \pm 3.0$ \\
\hline 73 & $2.1 \pm 0.5$ & $23.9 \pm 4.9$ & $23.4 \pm 1.5$ & $26.9 \pm 3.5$ & $31.6 \pm 2.1$ \\
\hline
\end{tabular}


slopes and intercepts from Expt. 1 (Fig. 1A), regression of root length did not differ over time for seedlings grown on various depths of leaf litter ( standard deviation of slopes $=0.009$, $0.019,0.031,0.065$, for $1.3-, 2.5-, 3.8-$, and 5.1-cm depths, respectively). The slopes of the regression lines for the $0.0-$ and $5.1-\mathrm{cm}$ leaf litter treatments were not statistically different from each other ( standard deviation $=0.056$ and 0.065 , respectively). However, the regression relationships for root growth over time differed significantly $(P<0.05)$ for seedlings grown in media with a sandy surface $(0.0-\mathrm{cm}$ leaf litter) vs. those grown in sand covered by $1.3,2.5$, or $3.8 \mathrm{~cm}$ of leaf litter. In the absence of surface organic matter, growth inhibition declined (i.e., less herbicide activity was detected) over time, while in the presence of any depth of organic matter, growth inhibition was maintained after $73 \mathrm{~d}$.

$T$ test comparisons of the slopes and intercepts of the regression lines (Fig. 1B) generated from the sanding study data confirmed this trend. The slopes of the regression lines from root growth response vs. time were statistically similar for alfalfa grown on organic matter covered by $1.3,2.5,3.8$, or $5.1 \mathrm{~cm}$ sand (standard deviation $=0.069,0.072,0.060$, 0.059 , respectively), with growth inhibition declining over time. In contrast, growth inhibition was maintained over time in the $0.0-\mathrm{cm}$ sand treatment in which the organic surface remained exposed, and the slope of the regression line (standard deviation $=0.005)$ was significantly different from the slopes of the 1.3-, 3.8-, and 5.1-cm sand treatments $(P<$ $0.05, P<0.01, P<0.01$, respectively) with a trend toward the same relationship with the $2.5-\mathrm{cm}$ sand treatment $(P<0.07)$.

In both experiments, herbicide activity, expressed as suppression of alfalfa root growth, was maintained for $>70 \mathrm{~d}$ when organic matter covered the surface. When the surface layer consisted of sand, herbicide activity declined over time. However, in Expt. 1, some herbicide activity persisted after $73 \mathrm{~d}$ when no organic matter was exposed. In this treatment, root growth on samples collected $73 \mathrm{~d}$ after herbicide application reached only $\approx 45 \%$ of that on samples collected prior to herbicide application (Table 1). In Expt. 2, herbicide activity in pots with surface sand declined over time relative to that in pots with leaf litter on the surface.

If these results reflect field conditions, $\approx 50 \%$ of the herbicide activity of dichlobenil would be lost 2 months after application to a recently sanded bed. Conversely, initial activity would be maintained after 2 months if the surface layer consisted of organic debris. However, herbicide activity in these studies was measured using alfalfa, known to be sensitive to dichlobenil (Malik et al., 1993). How activity against alfalfa root growth relates to efficacy of control for target cranberry weeds remains to be determined. Based on previous work (Dawson, 1970; Dawson et al., 1984), current research (H.A. Sandler and T.A. Bewick, unpublished data), and growers' field experiences, the levels of herbicide associated with $50 \%$ inhibition of alfalfa roots would probably be insufficient to control many target weeds, including dodder, in commercial cranberry production. If this is the case, control of dodder would be lost within 2 months of application.

Despite the uncertainty of the relationship between alfalfa bioassay results and field efficacy of dichlobenil, dichlobenil longevity in a cranberry bed appears to be reduced when sand is present as the surface layer. The influence of the cultural practice of sanding should be considered, especially when growers opt to use low-end dichlobenil rates for the control of dodder. In such situations, reduced weed control should be expected.

\section{Literature Cited}

Brady, N.C. and R.R. Weil. 1996. Nature and properties of soils, 11thed. Prentice-Hall, New York.

Davenport, J.R. and C.J. DeMoranville. 1993. A survey of several physical characteristics of cultivated cranberry bog soils in North America. Comm. Soil Sci. Plant Anal. 24:1769-1773.

Davenport, J.R., P.V. Oudemans, M.G. Hughes, and A. Lee. 1999. Evaluating commercial cranberry bogs for variability: Developing information for precision management, p. 907-913. In: P. Robert, R.H. Rust, and W.E. Larson (eds.). Proc. 4th Intl. Conf. on Precision Agr., Minneapolis-St. Paul 19-22 July 1998. ASA/CSSA/ SSSA Press, Madison, Wis.

Dawson, J.H. 1970. Dodder control in alfalfa with dichlobenil. Weed Sci. 18:225-230.

Dawson, J.H., F.M. Ashton, W.V. Welker, J.R. Frank, and G.A. Buchanan. 1984. Dodder and its control. U.S. Dept. Agr. Farmers' Bul. No. 2276.

DeMoranville, C.J. 1998. Flood management, p. 35-39. In: H.A. Sandler (ed.). Cranberry production: A guide for Massachusetts. Univ. of Massachusetts Ext. SP-127, East Wareham.

DeMoranville, C.J., H.A. Sandler, and T. Bicki. 1996. Sanding. In: Best management practices guide for cranberry production in Massachusetts. Univ. of Massachusetts Ext., East Wareham

Eck, P. 1990. The American cranberry. Rutgers Univ. Press, New Brunswick, N.J.

Franklin, H.J. 1951. Cranberry insects in Massachusetts, parts II-VII. Massachusetts Agr. Expt. Sta. Bul. 445.

Malik, N., G.G. Bowes, and J. Waddington. 1993. Residual herbicides for weed control in established alfalfa (Medicago sativa) grown for seed. Weed Technol. 7:483-490.

Murray, D.S. and P.W. Santelmann. 1980. Are herbicides present? Crops and Soils Mag. 32:1214.

Norman, M.A. and K.D. Patten. 1995. The mobility and persistence of dichlobenil in cranberry (Vaccinium macrocarpon Ait.) bogs. Weed Sci. Soc. Amer. 35:95. (Abstr.)

O'Donovan, J.T., A. Rashid, H.V. Nguyen, J.C. Newman, A. Khan, C.I. Johnson, R.E. Blackshaw, and K.N. Harker. 1996. A seedling bioassay for assessing the response of wild oat (Avena fatua) populations to triallate. Weed Technol. 10:931-935.

Parker, R. and A.G. Ogg. 1990. Crop bioassay for herbicide residues. Washington State Univ. EB 1417. Pullman, Wash

Sandler, H.A. and T.A. Bewick. 1999. Weed management, p. 18-32. In: H.A. Sandler, C.J. DeMoranville, and D. Cannon (eds.). Cranberry chart book-Management guide for Massachusetts. Univ. of Massachusetts Ext., East Wareham.

Sandler, H.A., M.J. Else, and M. Sutherland. 1997. Application of sand for inhibition of swamp dodder (Cuscuta gronovii) seedling emergence and survival on cranberry (Vaccinium macrocarpon) bogs. Weed Technol. 11:318-323.

SAS Institute. 1988. SAS user's guide, $6.03 \mathrm{ed}$. SAS Inst., Cary, N.C.

Strik, B.C. and A.P. Poole. 1995. Does sand application to soil surface benefit cranberry production? HortScience 30:47-49.

Tomlinson, B. 1937. Proper sanding of great importance in good bog management. Cranberries $1(9): 4,8-11$. 